\title{
Identification of intragenic methylation in the TUSC1 gene as a novel prognostic marker of hepatocellular carcinoma
}

\author{
DAI SHIMIZU, MITSURO KANDA, SHUJI NOMOTO, HISAHARU OYA, HIDEKI TAKAMI, \\ SOKI HIBINO, MASAYA SUENAGA, YOSHIKUNI INOKAWA, MITSUHIRO HISHIDA, \\ NAO TAKANO, YOKO NISHIKAWA, SUGURU YAMADA, TSUTOMU FUJII, GORO NAKAYAMA, \\ HIROYUKI SUGIMOTO, MASAHIKO KOIKE, MICHITAKA FUJIWARA and YASUHIRO KODERA
}

Department of Gastroenterological Surgery (Surgery II), Nagoya University Graduate School of Medicine, Nagoya, Japan

Received October 24,2013; Accepted November 20, 2013

DOI: 10.3892/or.2013.2939

\begin{abstract}
Patients with hepatocellular carcinoma (HCC) have a poor prognosis, and novel molecular targets for treating recurrence and progression of the disease along with associated biomarkers are urgently required. In the present study, expression and the regulatory mechanism of TUSC1 (tumor suppressor candidate 1) were investigated to determine if it is a candidate tumor suppressor gene for HCC, which shows repressed transcription that involves aberrant DNA methylation. TUSC1 mRNA expression levels in HCC cell lines and 94 pairs of surgical specimens were determined using quantitative real-time reverse transcription polymerase chain reaction assay. Methylation status of HCC cell lines and clinical samples were analyzed to investigate the regulatory mechanism of TUSC1 transcription and the relationship between the methylation status of the TUSC1 gene and clinicopathological factors. The expression and distribution of the TUSC1 protein in liver tissues were determined using immunohistochemistry. A majority of HCC cell lines (89\%) and surgical specimens (84\%) demonstrated reduced expression levels of TUSC1 mRNA compared with paired non-cancerous liver tissues. The mean mRNA expression level in HCC was significantly lower than in corresponding non-cancerous liver. In contrast, no significant difference was found in TUSC1 mRNA expression level between adjacent normal and cirrhotic liver tissue from HCC patients. The TUSC1 protein expression pattern in HCC and liver tissues was consistent with TUSC1 mRNA expression. Twenty-nine (31\%) of 94 patients showed intragenic hypermethylation of the TUSC1 gene in HCC, and hypermethylation was significantly associated with advanced pathological stage. Subsequently, patients with hypermethyl-
\end{abstract}

Correspondence to: Dr Mitsuro Kanda, Department of Gastroenterological Surgery (Surgery II), Nagoya University Graduate School of Medicine, 65 Tsurumai-cho, Showa-ku, Nagoya 466-8550, Japan

E-mail: m-kanda@med.nagoya-u.ac.jp

Key words: hepatocellular carcinoma, TUSC1, intragenic methylation, tumor suppressor ation of the TUSC1 gene had a significantly poorer prognosis than patients without hypermethylation. Our results suggest that TUSC1 is a candidate tumor suppressor gene and intragenic hypermethylation is one of the suppressive mechanisms that regulate TUSC1 transcription in HCC. Intragenic methylation of the TUSC1 gene may serve as a novel prognostic marker of HCC.

\section{Introduction}

Hepatocellular carcinoma (HCC) is the most common primary form of liver cancer and the third most fatal type of cancer globally, after lung and stomach cancer $(1,2)$. With $>750,000$ new cases diagnosed every year worldwide, HCC is the sixth most common neoplasm (3). The overall 5-year survival rate of liver cancer patients remains low, ranging from 0 to $14 \%$ (4). This is due to the fact that HCC is diagnosed at an advanced/ symptomatic stage in most patients, when limited therapeutic options such as surgery and topical therapy (including radiofrequency ablation) are available $(5,6)$. This illustrates the importance of elucidating the cellular and molecular mechanisms involved in this aggressive cancer to develop more effective treatment options and improve the prognosis of HCC patients.

Approximately $90 \%$ of HCC cases arise from cirrhosis and the disease is strongly associated with several risks factors, including hepatitis $\mathrm{B}$ and $\mathrm{C}$ infections, alcohol abuse, primary biliary cirrhosis, autoimmune hepatitis and nonalcoholic steatohepatitis $(7,8)$. Different players, including immune cells, hepatic stellate cells, and macrophages, react to liver injury by producing cytokines and components of the extracellular matrix, which promote angiogenesis and survival of damaged hepatocytes or cancer stem cells (9-12). This regenerative response favors the accumulation of mutations and epigenetic aberrations, which leads to malignant transformation of preneoplastic nodules $(2,13,14)$. However, similar to other types of cancer, the molecular mechanisms underlying the development and progression of $\mathrm{HCC}$ remain unclear.

DNA methylation is a major epigenetic mechanism of gene regulation occurring in eukaryotic DNA at $\mathrm{CpG}$ sites, which are generally enriched in the promoters of genes. In a wide range of tumors, including $\mathrm{HCC}$, global hypomethylation and 
specific promoter hypermethylation have been linked with genomic instability and inactivation of tumor suppressor genes (TSGs), which regulate a variety of important cellular networks including apoptosis, DNA repair, inflammation, cell adhesion and migration, as well as cell-cycle control (14-17). It has been shown that specific drugs can reverse hypermethylation, and, hence, the application of DNA demethylation has been investigated to explore its therapeutic ability to reactivate TSGs whose subsequent gene expression leads to the inhibition of tumor progression $(18,19)$. A number of DNA methylation inhibitors are currently under investigation, including azacytidine and decitabine. Since epigenetic alterations in cancer cells affect virtually every cellular pathway such as those involved in cell-cycle progression, angiogenesis, apoptosis, cell survival and immunogenicity, it is thought that epigenetic drugs will possess versatile antitumor activity $(18,20,21)$. In addition, abnormal hypermethylated genes in cancer can serve as biomarkers for early detection and tumor classification, and for monitoring response to treatments such as targeted therapy and epigenetic agents (22-24).

The tumor suppressor candidate 1 (TUSC1) gene, whose cytogenetic location is 9p21.2, was first identified as a potential lung cancer tumor suppressor gene in 2004 (25). Although TUSC1 was recently reported to suppress cell proliferation and tumorigenicity in non-small cell lung cancer, expression and epigenetic alteration of the TUSC1 gene in gastroenterological cancer including HCC have not been investigated $(26,27)$. Accordingly, we focused on TUSC1 and investigated the expression and regulatory mechanisms of TUSC1 in order to determine if TUSC1 is a TSG that is silenced through hypermethylation and if it is a novel epigenetic biomarker for hepatocarcinogenesis and HCC progression.

\section{Materials and methods}

Sample collection. Nine HCC cell lines (Hep3B, HepG2, HLE, HLF, HuH1, HuH2, HuH7, PLC/PRF/5 and SK-Hep1) were obtained from the American Type Culture Collection (Manassas, VA, USA), stored at $-80^{\circ} \mathrm{C}$ in a cell preservative solution (=Tokyo, Japan) and cultured in RPMI-1640 (SigmaAldrich, St. Louis, MO, USA) supplemented with $10 \%$ fetal bovine serum at $37^{\circ} \mathrm{C}$ in a $5 \% \mathrm{CO}_{2}$ atmosphere.

A 68-year-old woman with chronic hepatitis $\mathrm{C}$ was discovered to have an $\mathrm{HCC}, 3 \mathrm{~cm}$ in diameter, on the right lobe of her liver. A contrast-enhanced abdominal computed tomography (CT) scan showed a homogeneous mass. The patient underwent partial hepatectomy in 2007. Specimens from her tumor and corresponding non-cancerous tissue were immediately harvested, and total RNA was extracted for use in microarrays. The tumor was pathologically diagnosed as HCC, and an area containing $>80 \%$ of cancer cells was selected for RNA extraction.

Primary HCC tissues and corresponding non-cancerous tissues were collected consecutively from 94 patients undergoing liver resection for $\mathrm{HCC}$ at Nagoya University Hospital between January 1998 and July 2008. Specimens were classified histologically according to the 7th edition of the Union for International Cancer Control (UICC) classification (28). Background liver status, Child-Pugh classification, hepatitis virus infection, preoperative serum tumor markers, tumor multiplicity and maximum size, pathological findings including tumor differentiation and vascular invasion were investigated. The median duration of patient follow-up was 41.1 months (range, 0.8-147 months). Postoperative follow-up included physical examinations and measurement of serum tumor markers every three months, and enhanced CT scans (chest and abdominal cavity) every six months. Treatment after recurrence was generally selected from the following options: surgery, radiofrequency ablation, transcatheter arterial chemoembolization and chemotherapy according to tumor status and liver function.

Collected tissue samples were immediately flash frozen in liquid nitrogen and stored at $-80^{\circ} \mathrm{C}$ until RNA extraction (28 days on average) was performed. Tumor samples, $\sim 5 \mathrm{~mm}$ square, without the necrotic component and confirmed to contain $>80 \%$ tumor cells by definition, were used for RNA extraction. Corresponding non-cancerous liver tissue samples, collected $>2 \mathrm{~cm}$ away from the edge of the tumor, were obtained from the same patient and did not contain any regenerative or dysplastic nodules.

The study fully conformed to the ethical guidelines of the World Medical Association Declaration of Helsinki Ethical Principles for Medical Research Involving Human Subjects. Written informed consent for usage of clinical samples and data, as required by the Institutional Review Board at Nagoya University, Japan, was obtained from all enrolled patients.

Microarray procedure. Total RNA was isolated from each of the frozen samples using the RNeasy mini kit (Qiagen, Chatsworth, CA, USA) according to the manufacturer's protocol. Gene expression profiles were determined using Affymetrix HGU133A and HGU133B GeneChips (Affymetrix, Santa Clara, CA, USA) according to the manufacturer's recommendations. In brief, double-stranded cDNA was synthesized from $8 \mu \mathrm{g}$ of total RNA with oligo T7-(dt)24 as the primer and transcribed into biotinylated cRNA using an IVT labeling kit (Affymetrix). Biotinylated cRNA $(20 \mu \mathrm{g})$ was fragmented at $94^{\circ} \mathrm{C}$ for $35 \mathrm{~min}$ and hybridized to the human genome U133 Plus 2.0 gene chip array (Affymetrix), which contains $>54,000$ probe sets. The cRNA probes that hybridized to the oligonucleotide arrays were stained with streptavidin R-phycoerythrin and processed for signal intensity using Micro Array Suite 5.0 software (Affymetrix). All data used for subsequent analysis passed the quality control criteria.

Reverse transcription-polymerase chain reaction (RT-PCR) and quantitative real-time RT-PCR. TUSC1 mRNA expression was analyzed using RT-PCR and quantitative real-time RT-PCR. Total RNA $(10 \mu \mathrm{g})$ was isolated from HCC cell lines (Hep3B, HepG2, HLE, HLF, HuH1, HuH2, HuH7, PLC/PRF/5 and SK-Hep1), 94 primary HCCs and corresponding adjacent non-cancerous tissues and was used to generate cDNAs. They were then amplified using PCR primers for TUSC1; sense (S) (5'-ACATGTACAGTTCCCCTGCC-3' in exon 1) and antisense (AS) (5'-GTGTTTCTTGGCACCCAGTT-3' in exon 1), which amplify a 110 base pair (bp) product. The RT-PCR amplification protocol was: 40 cycles at $94^{\circ} \mathrm{C}$ for $15 \mathrm{sec}, 60^{\circ} \mathrm{C}$ for $15 \mathrm{sec}$, and $72^{\circ} \mathrm{C}$ for $20 \mathrm{sec}$, after an initial denaturation step at $94^{\circ} \mathrm{C}$ for $2 \mathrm{~min}$. RT-PCR of $\beta$-actin was also performed to 
confirm that equal amounts of cDNA were used as templates. Each RT-PCR product was loaded directly onto $2 \%$ agarose gels, stained with ethidium bromide and visualized under UV illumination. Quantitative real-time RT-PCR was performed using the SYBR-Green PCR core reagents kit (Perkin-Elmer, Applied Biosystems, Foster City, CA, USA) under the following conditions: one cycle at $95^{\circ} \mathrm{C}$ for $10 \mathrm{~min}$, then 45 cycles at $95^{\circ} \mathrm{C}$ for $15 \mathrm{sec}$ and $60^{\circ} \mathrm{C}$ for $30 \mathrm{sec}$. Real-time detection of the SYBR-Green emission intensity was conducted using an ABI prism 7000 Sequence Detector (Perkin-Elmer, Applied Biosystems). The primers for the PCR reaction were the same primers used for RT-PCR, as described above. For standardization purposes, the expression of glyceraldehyde-3-phosphate dehydrogenase (GAPDH) mRNA (TaqMan, GAPDH control reagents, Applied Biosystems) was quantified in each sample. Quantitative RT-PCR was performed using nine HCC cell lines and 94 clinical samples in triplicate and included samples without templates as negative controls. The expression level of each sample is shown as the value of TUSC1 divided by that of GAPDH.

Surveillance of the CpG island around the TUSC1 gene locus. The base sequence around the TUSC1 gene was analyzed for the presence of $\mathrm{CpG}$ islands to evaluate methylation as a potential regulatory mechanism of TUSC1 gene expression. The presence or absence of a $\mathrm{CpG}$ island was determined using the following criteria: at least 200-bp region of DNA with a high GC content (>50\%) and an observed $\mathrm{CpG} /$ expected $\mathrm{CpG}$ ratio of $\geq 0.6$ (29). We used the $\mathrm{CpG}$ Island Searcher (http:// cpgislands.usc.edu/) to determine the location of putative $\mathrm{CpG}$ islands (30).

Methylation-specific PCR (MSP). DNA samples extracted from HCC cell lines, clinical HCC tissues and corresponding non-cancerous tissues were subjected to bisulfite treatment. Briefly, $2 \mu \mathrm{g}$ of DNA was denatured with $\mathrm{NaOH}$ and modified using sodium bisulfite. DNA samples were then purified using Wizard purification resin (Promega, Madison, WI, USA), treated again with $\mathrm{NaOH}$, precipitated with ethanol, and resuspended in water. They were then amplified using unmethylated PCR primers located in exon 1 of the TUSC1 gene: S (5'-TGAGAGGATGAGTTGGGTAG-3') and AS (5'-CCCCACTCAAACATAATCCC-3'), which amplify a $121 \mathrm{bp}$ product. Primers used to detect methylated DNA were: S (5'-CGAGAGGACGAGTCGGGTAG-3') and AS (5'-CGC TCGAACGTAATCCCCGC-3') both in exon 1, which amplify a 118 bp product. The PCR amplification consisted of 40 cycles at $94^{\circ} \mathrm{C}$ for $15 \mathrm{sec}, 60^{\circ} \mathrm{C}$ for $15 \mathrm{sec}$, and $72^{\circ} \mathrm{C}$ for $20 \mathrm{sec}$, following an initial denaturation step at $94^{\circ} \mathrm{C}$ for $2 \mathrm{~min}$. Each PCR product was loaded directly onto $2 \%$ agarose gels, stained with ethidium bromide and visualized under UV illumination.

Bisulfite sequence analysis. Genomic bisulfite-treated DNAs from HCC cell lines were sequenced to verify the accuracy of the MSP results. The primer pair used to generate a fragment for sequencing was in exon 1 of TUSC1: S (5'-GGTAGTTT TAGGGTTTTGAG-3') and AS (5'-AAACTACTCCTCC TTATCCC-3'), which amplifies a 121 bp product. The PCR amplification protocol was as follows: 50 cycles at $94^{\circ} \mathrm{C}$ for
$20 \mathrm{sec}, 60^{\circ} \mathrm{C}$ for $20 \mathrm{sec}$, and $72^{\circ} \mathrm{C}$ for $20 \mathrm{sec}$, following an initial denaturation step at $94^{\circ} \mathrm{C}$ for $2 \mathrm{~min}$. PCR products were purified directly using the QIAquick PCR Purification kit (Qiagen, Hilden, Germany). Purified DNA fragments were subcloned into the TA cloning vector (Invitrogen, Carlsbad, CA, USA). Each cloned DNA was mixed with $3 \mu \mathrm{l}$ of specific primer (M13) and $4 \mu \mathrm{l}$ of Cycle Sequence Mix (ABI PRISM Terminator v1. 1 Cycle Sequencing kit; Applied Biosystems). Sequence analysis was carried out using an Applied Biosystems ABI310 and sequence electropherograms were generated using ABI Sequence Analysis 3.0 software.

5-Aza-2'-deoxycytidine (5-aza-dC) treatment. To assess the relationship between hypermethylation and TUSC1 mRNA expression, HCC cell lines were treated with the DNA methylation inhibitor 5-aza-dC (Sigma-Aldrich). Cells $\left(1.5 \times 10^{6}\right)$ were cultured for 6 days with medium changes on days 1, 3 and 5. After incubation, the cells were harvested, RNA was extracted, and RT-PCR was performed as described above.

Immunohistochemical staining. We used immunohistochemical staining to investigate TUSC1 protein localization in 35 representative HCC samples whose sections were well preserved. Formalin-fixed, paraffin-embedded tissue samples were dewaxed in xylene twice for $5 \mathrm{~min}$, rehydrated in graded alcohols 100,90 and $70 \%$ and $\mathrm{H}_{2} \mathrm{O}$ for 2 min each and subsequently treated with $3 \% \mathrm{H}_{2} \mathrm{O}_{2}$ to inhibit endogenous peroxidases, followed by antigen retrieval with $10 \mathrm{mM}$ citrate buffer at $95^{\circ} \mathrm{C}$ for $5 \mathrm{~min}$, repeated five times. The samples were incubated with Histofine SAB-PO ${ }^{\circledR}$ (Nichirei, Tokyo, Japan) for $5 \mathrm{~min}$ to limit nonspecific reactivity, and were then incubated for $1 \mathrm{~h}$ at room temperature with a rabbit antibody to TUSC1 (bs-6114R, Bioss Inc., Woburn, MA, USA), diluted 1:250 in ChemMatet antibody diluent (Dako, Carpinteria, CA, USA). Samples were then washed with phosphate-buffered saline, followed by $10 \mathrm{~min}$ incubation with biotinylated secondary antibody (Histofine SAB-PO, Nichirei). Sections were subsequently developed for $1 \mathrm{~min}$ using liquid 3,3'- diaminobenzidine (DAB) as the substrate (Nichirei). Staining properties were determined using blood vessels as internal controls, and staining patterns in HCCs were compared with corresponding non-cancerous tissues. To avoid subjectivity, specimens were randomized and coded before analysis by two independent observers, blinded to the status of the samples. Each observer evaluated all specimens at least twice within a given time interval to minimize intraobserver variation.

Statistical analysis. The relative mRNA expression levels (TUSC1/GAPDH) were calculated from quantified data. Differences in TUSC1 expression levels between two groups were analyzed using the Mann-Whitney U test. The association between the methylation status of TUSC1 and clinicopathological parameters was evaluated using the $\chi^{2}$ test. Disease-specific survival rates were calculated using the Kaplan-Meier method, and the difference in survival curves was analyzed using the generalized Wilcoxon test. All statistical analysis was performed using $\mathrm{JMP}^{\circledR} 10$ software (SAS Institute Inc., Cary, NC, USA). A p-value of $<0.05$ was considered to indicate statistically significant differences. 
Table I. Microarray results for TUSC1 expression.

\begin{tabular}{lccccccc}
\hline Gene symbol & $\begin{array}{c}\text { Log2 } \\
\text { ratio }\end{array}$ & $\begin{array}{c}\text { Normal } \\
\text { signal }\end{array}$ & Detection & $\begin{array}{c}\text { Tumor } \\
\text { signal }\end{array}$ & Detection & Probe ID & $\begin{array}{c}\text { Chromosomal } \\
\text { location }\end{array}$ \\
\hline TUSC1 & -3.4 & 252.1 & P & 25.6 & P & HU133p2_36644 & Chr 9p21.2 \\
\hline
\end{tabular}

\section{Results}

Patient characteristics. The ages of the 94 patients ranged from 34-84 years $(64.5 \pm 10.0$ years, mean $\pm \mathrm{SD})$, and the male to female ratio was 77:17. Twenty-six patients had hepatitis B and 53 had hepatitis $C$ infections. In terms of the non-cancerous liver, the number of patients with normal liver, chronic hepatitis and cirrhosis were 9,49 and 36, respectively. Eighty-seven patients were in Child-Pugh class A and 12 patients were in class $\mathrm{B}$. When classified according to the 7 th edition of the UICC classification, 11, 44, 29 and 10 patients were in stages I, II, III and IV, respectively.

Expression array. We conducted an expression array in order to find a new candidate TSG in HCC. We searched for genes whose expression in tumor tissues was reduced further than that in corresponding non-cancerous tissues, and TUSC1 expression was found to be reduced in HCC compared with normal tissue with a $\log 2$ ratio of -3.4 (Table I).

TUSC1 mRNA expression analyzed by quantitative RT-PCR . Reduced expression of TUSC1 mRNA was confirmed in all HCC cell lines, except for PLC/PRF/5, when compared with the median expression level in non-cancerous liver tissues (Fig. 1A). In particular, Hep3B, HepG2, HuH1 and $\mathrm{HuH} 2$ showed marked suppression of TUSC1 mRNA.

When TUSC 1 mRNA expression levels in non-cancerous tissue samples without cirrhosis $(n=58)$ were compared to those with cirrhosis $(n=36)$, no significant differences were found, suggesting that the expression of TUSC1 mRNA in non-cancerous liver was not affected by background liver fibrosis (Fig. 1B). In 79 (84\%) of 94 patients, the TUSC1 mRNA expression level was lower in HCC tissues than in corresponding normal tissues. Additionally, mean expression of TUSC1 mRNA was significantly lower in HCC tissues than in corresponding normal tissues ( $<<0.001$; Fig. 1C).

Identification of a $\mathrm{CpG}$ island. TUSC1 is an intronless gene. The CpG island was found inside exon 1 of the TUSC1 gene using the CpG Island Searcher; length, $1,315 \mathrm{bp}$; GC content $67.8 \%$ and an observed $\mathrm{CpG}$ /expected $\mathrm{CpG}$ ratio of 0.82 (Fig. 2). Accordingly, we hypothesized that hypermethylation of the intragenic $\mathrm{CpG}$ island is the mechanism responsible for regulating TUSC1 gene expression in $\mathrm{HCC}$ tissue.

MSP of HCC cell lines. MSP was conducted to verify the above hypothesis. We first examined the methylation status of nine HCC cell lines. Appropriate-sized MSP bands were confirmed in Hep3B, HepG2 and HuH2. Following PCR using unmethylated primers, appropriate-sized bands were confirmed in all HCC cell lines other than Hep3B and $\mathrm{HuH} 2$
A

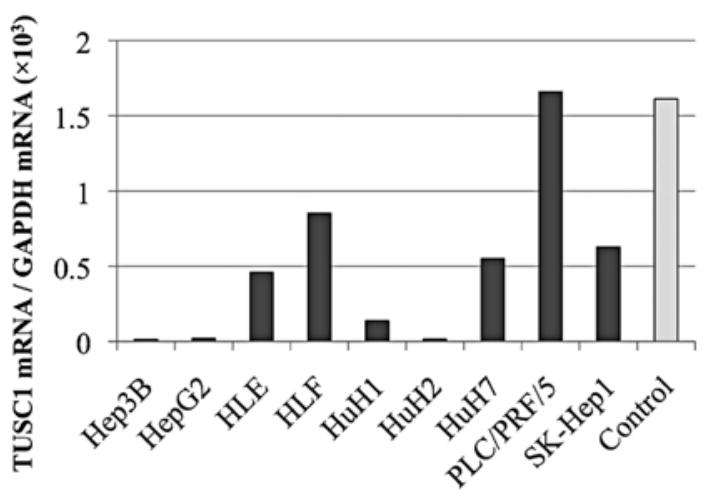

B

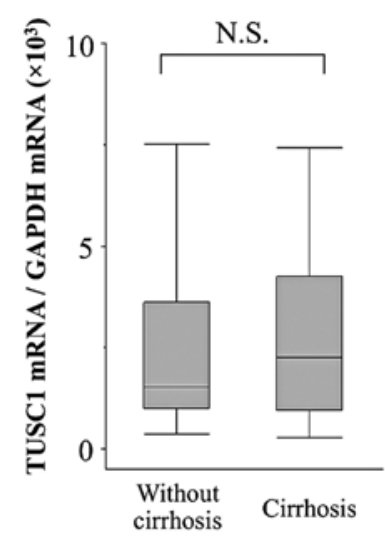

C

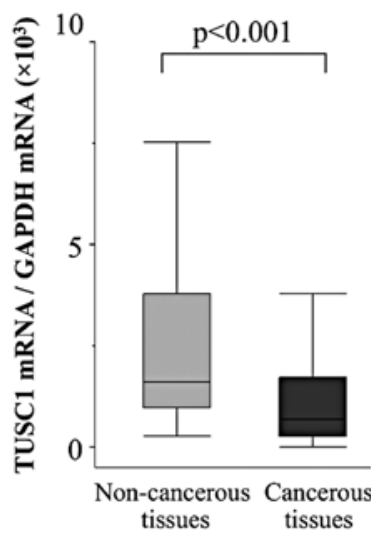

Figure 1. TUSC1 mRNA expression in HCC cell lines and control (94 surgical specimens of non-cancerous tissue) by quantitative real-time RT-PCR. (A) Reduced expression was confirmed in all HCC cell lines except for PLC/ $\mathrm{PRF} / 5$, compared with the control. (B) There were no significant differences in TUSC1 mRNA expression levels between patients with and without cirrhosis in the adjacent non-cancerous liver. (C) Mean expression of TUSC1 mRNA was significantly lower in HCC tissues than in corresponding normal tissues. NS, not significant.

(Fig. 3A). We concluded that complete methylation occurred in Hep3B and $\mathrm{HuH} 2$, with an absence of methylation in HLE, $\mathrm{HLF}, \mathrm{HuH1}, \mathrm{HuH} 7, \mathrm{PLC} / \mathrm{PRF} / 5$ and SK-Hep1, and only partial methylation in HepG2.

Expression of TUSC1 after 5-aza-dC treatment. To explore whether intragenic hypermethylation leads to the suppression of expression, we examined the expression of TUSC1 in HCC cell lines before and after treatment with the DNA methylation inhibitor, 5-aza-dC. Applying semi-quantitative RT-PCR, a reactivation or increase in TUSC1 expression was shown to occur in $\mathrm{Hep} 3 \mathrm{~B}, \mathrm{HepG} 2$ and $\mathrm{HuH} 2$ cells in agreement with the MSP results (Fig. 3B). 


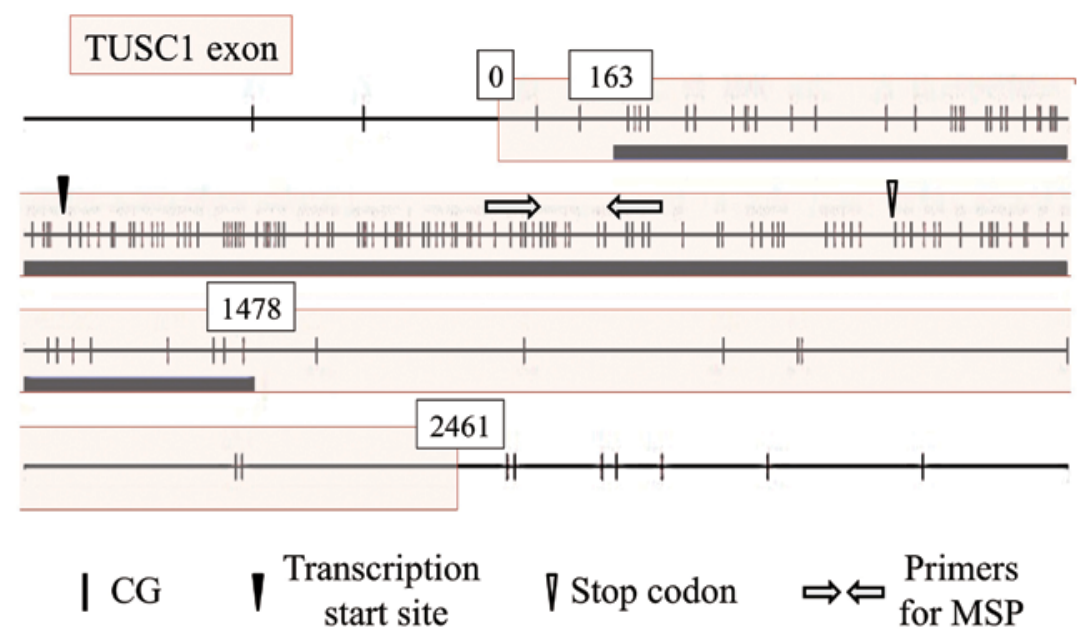

CpG island

Lengh 1315 bp, \%GC 67.8\%, Observed CpG / Expected $\mathrm{CpG}=0.82$

Figure 2. Map overview of the TUSC1 gene. The CpG island was found inside the exon of the TUSC1 gene.

A

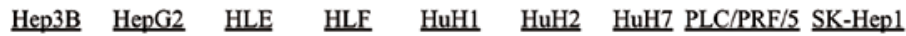

UM $M$ UM $M$ UM $M$ UM $M$ UM $M$ U UM $M$ U UM $M$ M UM $M$

TUSC1

B

5-aza-dC $\underline{\underline{H e p 3 B}} \underline{-} \underline{\underline{H} \text { epG2 }} \underline{\underline{H L E}} \quad \underline{\mathrm{HLF}} \quad \underline{\mathrm{HuH1}} \quad \underline{\mathrm{HuH} 2} \quad \underline{\mathrm{HuH} 7} \underline{\mathrm{PLC} / \mathrm{PRF} / 5} \underline{\mathrm{SK}-\mathrm{Hep} 1}$

TUSC1 $\equiv-----------$

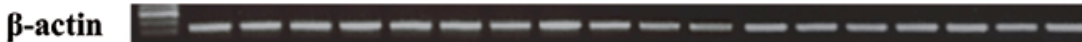

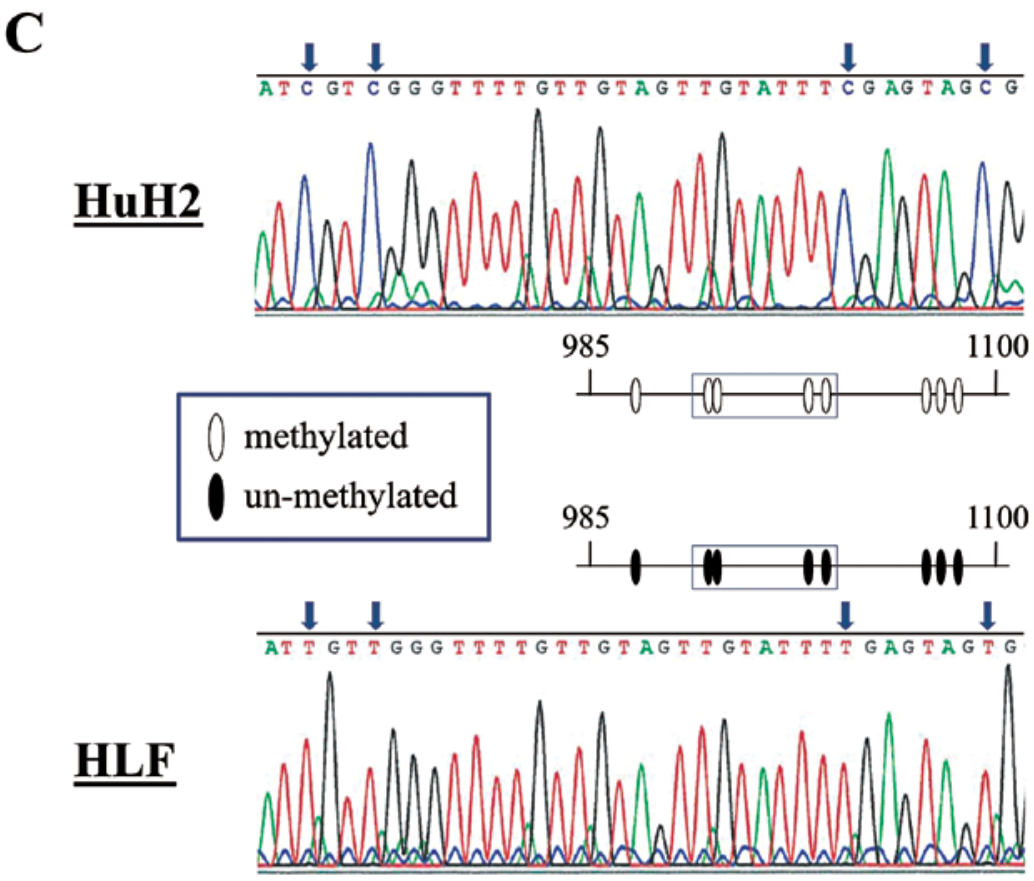

Figure 3. Results of methylation-specific PCR (MSP). (A) Complete methylation occurred in Hep3B and HuH2, there was an absence of methylation in HLE, HLF, HuH1, HuH7, PLC/PRF/5 and SK-Hep1, and partial methylation was present in HepG2. (B) RT-PCR before and after 5-aza-dC treatment. Reactivation or increase in TUSC1 expression occurred in Hep3B, HepG2 and HuH2 cells. (C) Bisulfite sequence analysis of HuH2 and HLF cells. All CpGs in HuH2 cells were CG, while all those in HLF were TG. 


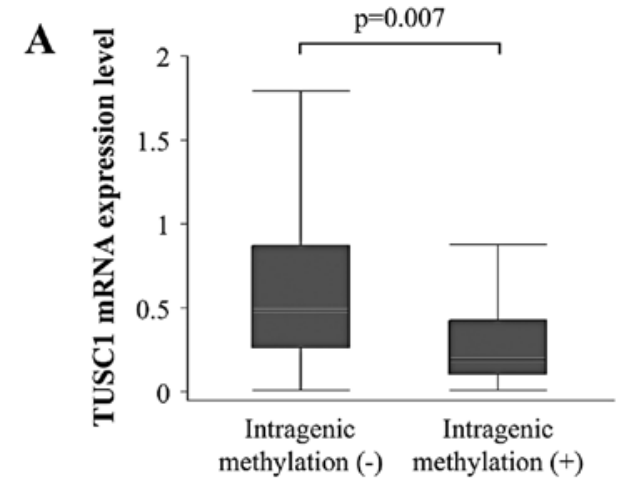

B

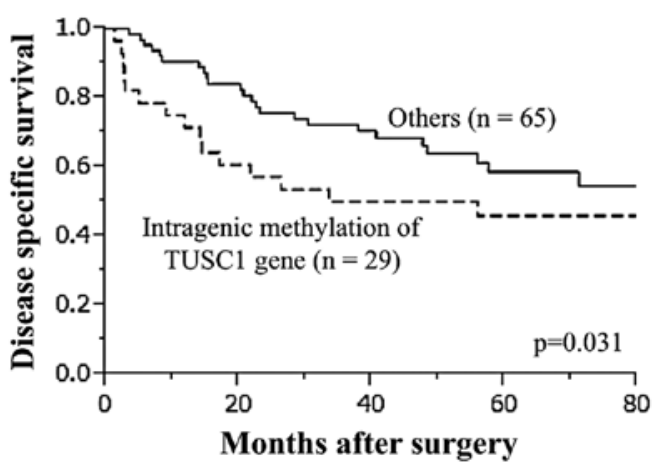

Figure 4. (A) Mean expression of TUSC1 mRNA was significantly lower in patients with intragenic hypermethylation than in those without intragenic hypermethylation ( $\mathrm{p}=0.007)$. (B) Kaplan-Meier analysis of survival in 94 patients, categorized as having intragenic hypermethylation of the TUSC1 gene in HCC tissues and the others. The p-value was calculated using the generalized Wilcoxon test.

Bisulfite sequence analysis. To ascertain whether the MSP amplification was performed reliably, we conducted a direct sequence analysis of HuH2 (complete methylation in MSP) and HLF (absence of methylation in MSP). We found that all CpGs in the HuH2 fragment were CG, while all those in HLF were TG (Fig. 3C). These results indicated that the MSP had worked correctly.

Expression and methylation status of TUSC1 in 94 clinical HCC samples. Downregulation of TUSC1 mRNA was observed in 79 of 94 (84.0\%) tumor samples from patients with HCC and there was no significant association with overall or recurrence-free survival.

Using MSP, 29 (30.9\%) of 94 HCC tissues and only two (2.1\%) of 94 corresponding non-cancerous tissues showed intragenic hypermethylation in the TUSC1 gene. The TUSC1 mRNA expression level in HCC patients with intragenic methylated TUSC1 was significantly lower than in those without, indicating that intragenic methylation contributed to the strong suppression of TUSC1 transcription (Fig. 4A). Moreover, disease-specific survival was significantly shorter in patients with intragenic hypermethylation of TUSC1 than in those without ( $\mathrm{p}=0.031$; Fig. 4B).

Analysis of the association between the methylation status of TUSC1 and clinicopathological factors including demographics, background liver status and pathological findings showed that intragenic hypermethylation of TUSC1 in HCC was significantly associated with advanced UICC stage $(\mathrm{p}=0.025$; Table II $)$.
Table II. Association between methylation status of TUSC1 and clinicopathological parameters in 94 HCC patients.

\begin{tabular}{|c|c|c|}
\hline $\begin{array}{l}\text { Clinicopathological } \\
\text { parameters }\end{array}$ & $\begin{array}{c}\text { Methylation } \\
\text { positive } \\
\text { in tumor } \\
\text { tissues (n) }\end{array}$ & $\begin{array}{c}\text { Methylation } \\
\text { negative } \\
\text { in tumor } \\
\text { tissues (n) }\end{array}$ \\
\hline
\end{tabular}

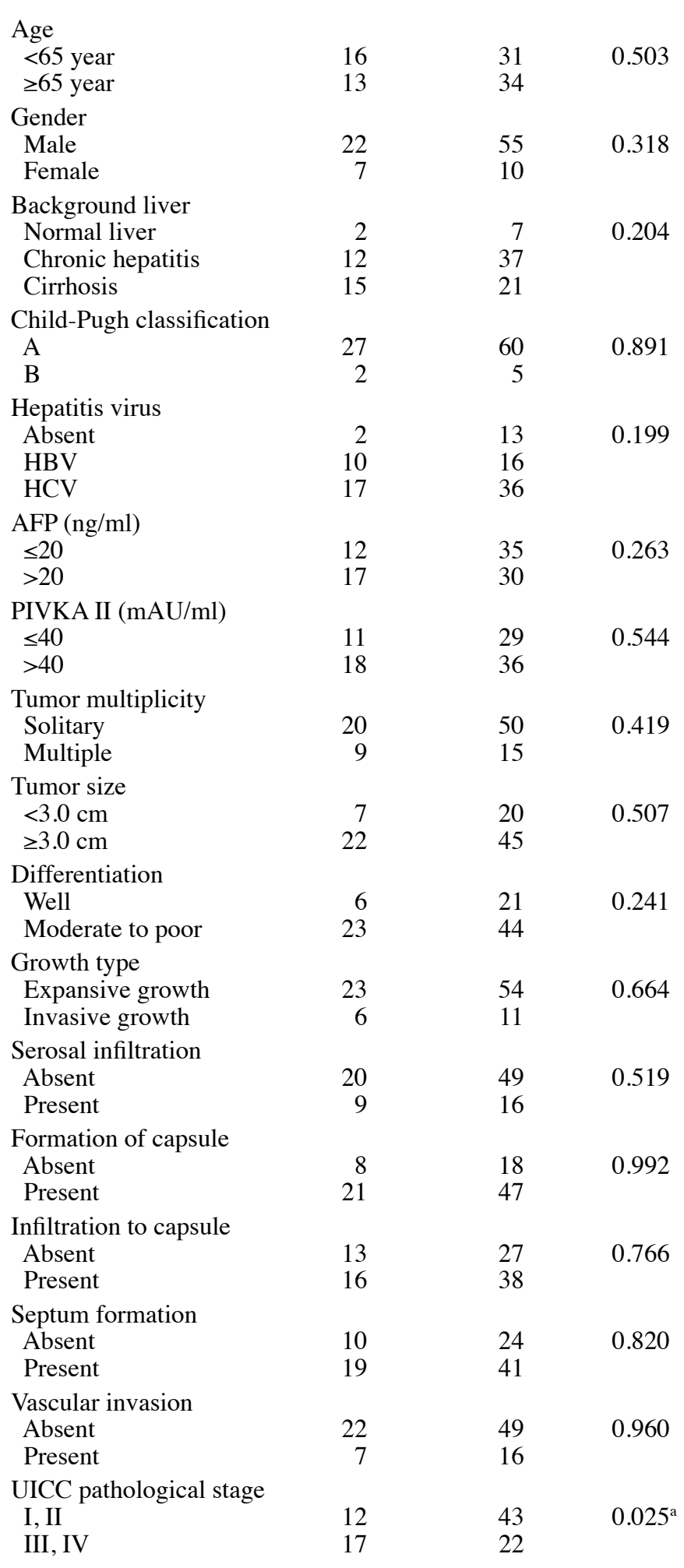

UICC, Union for International Cancer Control; HBV, hepatitis B virus; $\mathrm{HCV}$, hepatitis C virus; AFP, $\alpha$-fetoprotein; PIVKA, protein induced by vitamin $\mathrm{K}$ antagonists; $\mathrm{S}$, serosal infiltration; Fc, formation of capsule; $\mathrm{Fc}$-inf, infiltration to capsule. ${ }^{\mathrm{a}}$ Statistically significant difference $(\mathrm{p}<0.05)$. 


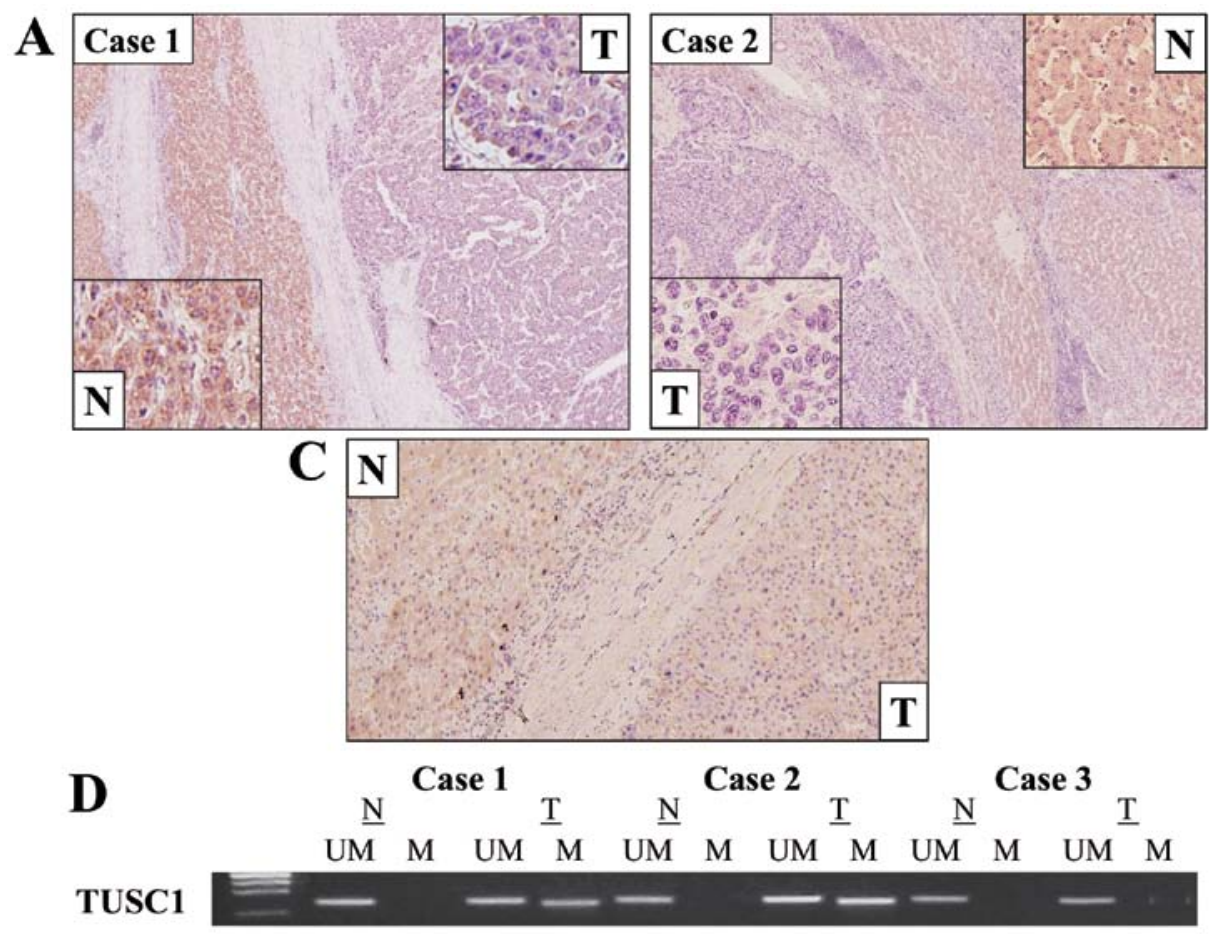

Figure 5. Detection of TUSC1 protein by immunohistochemical staining in representative tissues from HCC patients. (A) Case 1; (B) case 2, cancerous tissue components showed reduced expression levels of the TUSC1 protein compared with adjacent non-cancerous tissue components (magnification, $\mathrm{x} 40$ and x200). (C) Case 3, equivalent expression of the TUSC1 protein was confirmed in both cancerous and non-cancerous tissue components in patients without down-regulation of TUSC1 mRNA (magnification, x40). (D) Methylation-specific PCR results for cases 1-3, for which immunohistochemical staining is shown in (A-C). N, non-cancerous tissue component; $\mathrm{T}$, tumor tissue component.

Immunohistochemical staining. Next, immunohistochemical staining was performed to examine the expression of the TUSC1 protein in cases showing underexpressed and equivalent TUSC1 mRNA levels in HCC tissues relative to corresponding non-cancerous tissues. Two representative cases with downregulation of TUSC1 mRNA expression in HCC tissues showed reduced expression of TUSC1 protein in the cytoplasm of cancerous components compared with adjacent non-cancerous tissue components (Fig. 5A and B). Equivalent expression of TUSC1 protein both in cancerous and non-cancerous components was confirmed in the case without downregulation of TUSC1 mRNA expression in HCC (Fig. 5C). MSP results of the cases presented are shown in Fig. 5D. Overall, results of immunohistochemical staining were consistent with quantitative real-time PCR data for TUSC1.

\section{Discussion}

In the present study, we investigated the expression and methylation status of TUSC1 identified as a candidate TSG in HCC based on our microarray results. Consequently, the attenuated mRNA expression of TUSC1 in most of the cancer tissues compared with non-cancerous adjacent tissues implicated its role as a TSG. Given that TUSC1 mRNA expression was independent of progression of hepatic fibrosis, suppression of TUSC1 could be considered as a specific event that occurs in the final stage in the development of HCC.

Our analysis of the TUSC1 gene sequence showing that the gene possessed a $\mathrm{CpG}$ island inside exon 1 suggested that aberrant methylation was a potential mechanism regulating TUSC1 gene expression, although there have been no reports related to methylation analysis of the TUSC1 gene. TUSC1 transcription in Hep3B, HepG2 and $\mathrm{HuH} 2$ cells was markedly reduced, coinciding with intragenic hypermethylation. In surgical specimens, HCC tissues with intragenic hypermethylation of the TUSC1 gene displayed significantly lower expression of TUSC1 mRNA, and were associated with advanced UICC stage and, subsequently, an adverse prognosis. These results indicated that intragenic hypermethylation of the TUSC1 gene downregulated transcription and could be useful as a prognostic marker of HCC.

Alteration of chromosome $9 \mathrm{p}$ is implicated in a variety of tumor types including HCC through chromosomal inversions, translocations, loss of heterozygosity $(\mathrm{LOH})$ and homozygous deletion, suggesting that chromosome $9 \mathrm{p}$ contains a tumor suppressor locus critical in the development of tumors (31-34). Two candidate tumor suppressor loci were identified in the chromosome $9 \mathrm{p} 21$ region. One locus was p16/CDKN2A and the other p15/CDKN2B $(35,36)$. P16/CDKN2A is one of the major TSGs $(32,34,35)$. The TUSC1 gene was newly identified on chromosome 9p21.2 in 2004 and found to have tumor suppressor activity in lung cancer $(25,27)$. The TUSC1 locus is distinct from that of p16/CDKN2A and approximately $3.7 \mathrm{Mb}$ proximal to p16/CDKN2A (25). TUSC1 has unique features including an intronless structure and an intragenic $\mathrm{CpG}$ island as shown in Fig. 2. Although potential roles played by the TUSC1 gene have been investigated only in lung cancer, our results provide new insight into understanding the function of TUSC1. 
As shown in this study, TUSC1 possesses a CpG island inside exon 1, not in the promoter region, and intragenic hypermethylation was related to downregulation of TUSC1 mRNA. Recently, the role of intragenic methylation has led to a heated discussion amongst researchers. Since the 1970s, DNA methylation has been described as a silencing epigenetic mark that occurred in the promoter region (37). Improvement of genomescale mapping of methylation has enabled the evaluation of DNA methylation in the following different genomic contexts: transcriptional start sites with or without $\mathrm{CpG}$ islands, in gene bodies, in regulatory elements and in repeat sequences $(37,38)$. In recent studies, the majority of methylated $\mathrm{CpG}$ islands were shown to be in intragenic and intergenic regions, whereas $<3 \%$ of $\mathrm{CpG}$ islands in 5' promoters were methylated (38).

Although it is known that the methylation of DNA in promoter regions suppresses gene transcription, the role of DNA methylation in gene bodies remains unclear. Tissuespecific intragenic methylation might reduce, or, paradoxically, enhance transcription elongation efficiency (39-41). In this study, intragenic hypermethylation of the TUSC1 gene was confirmed in some HCC cell lines and clinical HCC tissues and was related to downregulation of TUSC1 gene transcription. However, it is highly controversial if hypermethylation of the TUSC1 gene can be considered as intragenic methylation, as is the case with other genes that possess introns and are of longer gene lengths, as the TUSC1 gene is intronless and consists of only 2,461 bases. There is a possibility that the transcription regulatory site and transcription site are overlapping one another. Although our results demonstrated that methylation of the TUSC1 gene played a role in transcriptional regulation, intragenic hypermethylation was not always confirmed in HCC cell lines and clinical HCC tissues in which downregulation of TUSC1 mRNA occurred. LOH could be another regulatory factor of TUSC1 transcription since chromosome $9 \mathrm{p}$ was reported to be a frequent site of $\mathrm{LOH}$ in HCC (33).

This study is limited by its lack of sufficient functional analysis of the TUSC1 gene; thus, we were unable to state conclusively that TUSC1 is a TSG in HCC. Further studies are required to clarify the molecular mechanisms underlying the biological activities of TUSC1 in HCC.

In summary, TUSC1 is a putative TSG in HCC. Intragenic methylation of the TUSC1 gene was one of the regulatory mechanisms of TUSC1 mRNA transcription and TUSC1 could be a novel prognostic marker of HCC.

\section{References}

1. Llovet JM, Burroughs A and Bruix J: Hepatocellular carcinoma Lancet 362: 1907-1917, 2003.

2. Hernandez-Gea V, Toffanin S, Friedman SL and Llovet JM: Role of the microenvironment in the pathogenesis and treatment of hepatocellular carcinoma. Gastroenterology 144: 512-527, 2013.

3. Jemal A, Bray F, Center MM, Ferlay J, Ward E and Forman D: Global cancer statistics. CA Cancer J Clin 61: 69-90, 2011.

4. Siegel R, Ward E, Brawley O and Jemal A: Cancer statistics, 2011: the impact of eliminating socioeconomic and racial disparities on premature cancer deaths. CA Cancer J Clin 61: 212-236, 2011

5. Yang JD and Roberts LR: Hepatocellular carcinoma: a global view. Nat Rev Gastroenterol Hepatol 7: 448-458, 2010.

6. Kanda M, Nomoto S, Nishikawa Y, Sugimoto H, Kanazumi N, Takeda $\mathrm{S}$ and Nakao A: Correlations of the expression of vascular endothelial growth factor B and its isoforms in hepatocellular carcinoma with clinico-pathological parameters. J Surg Oncol 98: 190-196, 2008.
7. Sanyal AJ, Yoon SK and Lencioni R: The etiology of hepatocellular carcinoma and consequences for treatment. Oncologist 15: 14-22, 2010.

8. Khare S, Zhang Q and Ibdah JA: Epigenetics of hepatocellular carcinoma: Role of microRNA. World J Gastroenterol 19: 5439-5445, 2013.

9. Villanueva A, Hoshida Y, Toffanin S, Lachenmayer A, Alsinet C, Savic R, Cornella H and Llovet JM: New strategies in hepatocellular carcinoma: genomic prognostic markers. Clin Cancer Res 16: 4688-4694, 2010.

10. Seitz HK and Stickel F: Risk factors and mechanisms of hepatocarcinogenesis with special emphasis on alcohol and oxidative stress. Biol Chem 387: 349-360, 2006.

11. Levental KR, Yu H, Kass L, Lakins JN, Egeblad M, Erler JT, Fong SF, Csiszar K, Giaccia A, Weninger W, Yamauchi M, Gasser DL and Weaver VM: Matrix crosslinking forces tumor progression by enhancing integrin signalling. Cell 139: 891-906, 2009.

12. Yates LR and Campbell PJ: Evolution of the cancer genome. Nat Rev Genet 13: 795-806, 2012.

13. Coulon S, Heindryckx F, Geerts A, Van Steenkiste C, Colle I and Van Vlierberghe H: Angiogenesis in chronic liver disease and its complications. Liver Int 31: 146-162, 2011.

14. Sawan C, Vaissiere T, Murr R and Herceg Z: Epigenetic drivers and genetic passengers on the road to cancer. Mutat Res 642: $1-13,2008$.

15. Kanda M, Nomoto S, Okamura Y, Hayashi M, Hishida M, Fujii T, Nishikawa Y, Sugimoto H, Takeda S and Nakao A: Promoter hypermethylation of fibulin 1 gene is associated with tumor progression in hepatocellular carcinoma. Mol Carcinog 50: 571-579, 2011.

16. Jones PA and Baylin SB: The epigenomics of cancer. Cell 128: 683-692, 2007.

17. Kanda M, Nomoto S, Okamura Y, Nishikawa Y, Sugimoto $H$, Kanazumi N, Takeda S and Nakao A: Detection of metallothionein $1 \mathrm{G}$ as a methylated tumor suppressor gene in human hepatocellular carcinoma using a novel method of double combination array analysis. Int J Oncol 35: 477-483, 2009.

18. Dango S, Mosammaparast N, Sowa ME, Xiong LJ, Wu F, Park K, Rubin M, Gygi S, Harper JW and Shi Y: DNA unwinding by ASCC3 helicase is coupled to ALKBH3-dependent DNA alkylation repair and cancer cell proliferation. Mol Cell 44: 373-384, 2011.

19. Youngblood B, Oestreich KJ, Ha SJ, Duraiswamy J, Akondy RS, West EE, et al: Chronic virus infection enforces demethylation of the locus that encodes PD-1 in antigen-specific CD8(+) T cells. Immunity 35: 400-412, 2011.

20. Um TH, Kim H, Oh BK, Kim MS, Kim KS, Jung G and Park YN: Aberrant $\mathrm{CpG}$ island hypermethylation in dysplastic nodules and early HCC of hepatitis B virus-related human multistep hepatocarcinogenesis. J Hepatol 54: 939-947, 2011.

21. Lao V and Grady W: Epigenetics and colorectal cancer. Nat Rev Gastroenterol Hepatol 8: 686-700, 2011.

22. Yuan Y, Wang J, Li J, Wang L, Li M, Yang Z, Zhang C and Dai JL: Frequent epigenetic inactivation of spleen tyrosine kinase gene in human hepatocellular carcinoma. Clin Cancer Res 12: 6687-6695, 2006.

23. Moribe T, Iizuka N, Miura T, Kimura N, Tamatsukuri S, Ishitsuka H, Hamamoto Y, Sakamoto K, Tamesa T and Oka M: Methylation of multiple genes as molecular markers for diagnosis of a small, well-differentiated hepatocellular carcinoma. Int J Cancer 125: 388-397, 2009.

24. Kanda M, Nomoto S, Oya H, Takami H, Hibino S, Hishida M, Suenaga M, Yamada S, Inokawa Y, Nishikawa Y, Asai M, Fujii T, Sugimoto $\mathrm{H}$ and Kodera Y: Downregulation of $D E N N D 2 D$ by promoter hypermethylation is associated with early recurrence of hepatocellular carcinoma. Int J Oncol 44: 44-52, 2014.

25. Shan Z, Parker T and Wiest JS: Identifying novel homozygous deletions by microsatellite analysis and characterization of tumor suppressor candidate 1 gene, TUSC1, on chromosome $9 \mathrm{p}$ in human lung cancer. Oncogene 23: 6612-6620, 2004.

26. Yang XR, Liang X, Pfeiffer RM, Wheeler W, Maeder D, Burdette L, Yeager M, Chanock S, Tucker MA and Goldstein AM: Associations of 9 p21 variants with cutaneous malignant melanoma, nevi, and pigmentation phenotypes in melanomaprone families with and without CDKN2A mutations. Fam Cancer 9: 625-633, 2010.

27. Shan Z, Shakoori A, Bodaghi S, Goldsmith P, Jin J and Wiest JS: TUSC1, a putative tumor suppressor gene, reduces tumor cell growth in vitro and tumor growth in vivo. PLoS One 8: e66114, 2013. 
28. Sobin LH, Gospodarowicz MK and Wittekind C (eds) UICC TNM classification of malignant tumours. 7th edition. Wiley-Liss, New York, 2009.

29. Takai D and Jones PA: Comprehensive analysis of CpG islands in human chromosomes 21 and 22. Proc Natl Acad Sci USA 99: 3740-3745, 2002.

30. Takai D and Jones PA: The CpG island searcher: a new WWW resource. In Silico Biol 3: 235-240, 2003.

31. Mead LJ, Gillespie MT, Hung JY, Rane US, Rayeroux KC, Irving LB and Campbell LJ: Frequent loss of heterozygosity in early non-small cell lung cancers at chromosome 9p21 proximal to the CDKN2a gene. Int J Cancer 71: 213-217, 1997.

32. Wiest JS, Franklin WA, Otstot JT, Forbey K, Varella-Garcia M, Rao K, Drabkin H, Gemmill R, Ahrent S, Sidransky D, Saccomanno G, Fountain JW and Anderson MW: Identification of a novel region of homozygous deletion on chromosome $9 p$ in squamous cell carcinoma of the lung: the location of a putative tumor suppressor gene. Cancer Res 57: 1-6, 1997.

33. Sheu JC, Lin YW, Chou HC, Huang GT, Lee HS, Lin YH Huang SY, Chen CH, Wang JT, Lee PH, Lin JT, Lu FJ and Chen DS: Loss of heterozygosity and microsatellite instability in hepatocellular carcinoma in Taiwan. Br J Cancer 80: 468-476, 1999.

34. Pollock P, Welch J and Hayward N: Evidence for three tumor suppressor loci on chromosome $9 \mathrm{p}$ involved in melanoma development. Cancer Res 61: 1154-1161, 2001.

35. Cairns P, Polascik TJ, Eby Y, Tokino K, Califano J, Merlo A, Mao L, Herath J, Jenkins R, Westra W, Rutter J, Buckler A, Gabrielson E, Tockman M, Cho K, Hedrick L, Bova G, Isaacs W, Koch W, Schwab D and Sidransky D: Frequency of homozygous deletion at p16/CDKN2 in primary human tumours. Nat Genet 11: $210-212,1995$
36. Serrano M, Hannon GJ and Beach D: A new regulatory motif in cell-cycle control causing specific inhibition of cyclin D/CDK4. Nature 366: 704-707, 1993.

37. Jones PA: Functions of DNA methylation: islands, start sites, gene bodies and beyond. Nat Rev Genet 13: 484-492, 2012.

38. Maunakea AK, Nagarajan RP, Bilenky M, Ballinger TJ, D'Souza C, Fouse SD, Johnson BE, Hong C, Nielsen C, Zhao Y, Turecki G, Delaney A, Varhol R, Thiessen N, Shchors K, Heine VM, Rowitch DH, Xing X, Fiore C, Schillebeeckx M, Jones SJ, Haussler D, Marra MA, Hirst M, Wang T and Costello JF: Conserved role of intragenic DNA methylation in regulating alternative promoters. Nature 466: 253-257, 2010.

39. Flanagan $J$ and Wild L: An epigenetic role for noncoding RNAs and intragenic DNA methylation. Genome Biol 8: 307, 2007.

40. Lorincz M, Dickerson D, Schmitt M and Groudine M: Intragenic DNA methylation alters chromatin structure and elongation efficiency in mammalian cells. Nat Struct Mol Biol 11: 1068-1075, 2004.

41. Ball M, Li JB, Gao Y, Lee JH, LeProust EM, Park IH, Xie B, Daley GQ and Church GM: Targeted and genome-scale strategies reveal gene-body methylation signatures in human cells. Nat Biotechnol 27: 361-368, 2009. 